\title{
Formación de Hidrocarburos Aromáticos Policíclicos (PAH) en la Pirólisis de Isómeros del Butanol a diferentes Temperaturas
}

\author{
Fausto Viteri ${ }^{1,2}$, Sandra Gracia ${ }^{1}$, Ángela Millera ${ }^{1}$, Rafael Bilbao ${ }^{1}$, María U. Alzueta ${ }^{1}$ \\ ${ }^{1}$ Grupo de Procesos Termoquímicos (GPT) \\ Instituto de Investigación en Ingeniería de Aragón (I3A). \\ Universidad de Zaragoza, Mariano Esquillor s/n, 50018, Zaragoza, España. \\ Tel. +34-976762707, e-mail: fviteri@unizar.es \\ ${ }^{2}$ Universidad Tecnológica Equinoccial, Quito, Ecuador
}

\begin{abstract}
El butanol, incluyendo sus 4 isómeros, actualmente presenta especial interés como biocombustible de segunda generación, pudiendo utilizarse como aditivo al combustible diésel, por su compatibilidad con éste.

El presente trabajo se centra en el estudio de la influencia de la temperatura sobre la formación de hidrocarburos aromáticos policíclicos (PAH) y hollín, durante la pirólisis de los cuatro isómeros del butanol: 1-butanol, 2-butanol, iso-butanol y tercbutanol.
\end{abstract}

\section{Introducción}

Los alcoholes se encuentran entre los compuestos para automoción más estudiados en los últimos años. Entre ellos, hay destacar el etanol (de primera generación) como uno de los más usados a nivel mundial ya sea como biocombustible o aditivo a los combustibles convencionales, debido a que puede ser obtenido a partir de fuentes renovables $\mathrm{y}$, además, posee potencial para reducir las emisiones de partículas y gases de efecto invernadero en motores de automoción. Sin embargo, en los últimos años, los biocombustibles de segunda generación (incluido etanol) han recibido atención, ya que son obtenidos sin presentar una amenaza para la seguridad alimentaria al poder producirse a partir de cultivos no comestibles. Entre ellos, el 1-butanol es uno de los más estudiados, ya que tiene características físico-químicas parecidas al diésel, como un alto poder calorífico, viscosidad, y número de cetano.

Varios estudios han demostrado la capacidad del 1butanol para reducir las emisiones de hollín y gases contaminantes, en motores de automoción [1, 2]. Así, un estudio realizado por nuestro grupo de investigación [3] mostró que, efectivamente, se obtenía un menor rendimiento a hollín y una mayor formación de $\mathrm{CO}$ y $\mathrm{CO}_{2}$, cuando se adicionaba 1- butanol en la pirólisis de acetileno (importante precursor de hollín). No obstante, la formación de PAH durante la pirólisis de 1-butanol y sus iómeros no se ha estudiado hasta la fecha.

El presente estudio investiga la formación de PAH y hollín a partir de la pirólisis de los cuatro isómeros de butanol: 1-butanol, 2-butanol, iso-butanol y tercbutanol. Se han analizado 16 hidrocarburos aromáticos policíclicos (PAH), clasificados por la Agencia de Protección Ambiental (EPA) como contaminantes prioritarios debido a su potencial cancerígeno. Los $16 \mathrm{PAH}$ analizados han sido: Naftaleno (NAPH), Acenaftileno (ACNY), Acenafteno (ACN), Fluoreno (FLUO), Fenantreno (PHEN), Antraceno (ANTH), Fluoranteno (FANTH), Pireno (PYR), Benzo[a]antraceno (B[a]A), Criseno (CHR), Benzo[b]fluoranteno $(\mathrm{B}[\mathrm{b}] \mathrm{F})$, Benzo[k]fluoranteno $(\mathrm{B}[\mathrm{k}] \mathrm{F})$, Benzo [a] pireno $(\mathrm{B}[\mathrm{a}] \mathrm{P})$, Dibenzo $[\mathrm{a}, \mathrm{h}]$ antraceno $(\mathrm{DB}[\mathrm{ah}] \mathrm{A})$, Benzo [g,h,i] perileno (B[ghi]P), Indeno[1,2,3$\mathrm{c}, \mathrm{d}]$ pireno $(\mathrm{I}[123-\mathrm{cd}] \mathrm{P})$.

\section{Metodología}

Los experimentos de pirólisis fueron llevados a cabo bajo condiciones de laboratorio bien controladas, en una instalación experimental descrita en detalle en trabajos anteriores [3, 4], a tres temperaturas: 1275 , 1375 y $1475 \mathrm{~K}$. La concentración en fase gas de los isómeros del butanol fue fijada en 22500 ppm, la cual se obtuvo a partir del isómero en fase líquida con ayuda de una bomba isocrática HPLC y una línea calefactada. El hollín se recolectó en un cartucho de fibra de cuarzo, situado al final del sistema de reacción. Los PAH formados en la fase gas se capturaron en una resina XAD-2, la cual se colocó después del recolector de hollín. Las paredes del reactor se lavaron con diclorometano para recolectar los PAH adheridos. Se usó un cromatógrafo de gases para analizar hidrocarburos ligeros. Al finalizar cada experimento, las muestras sólidas de hollín y de la resina, se sometieron a una 
extracción Soxhlet y, posteriormente, el extracto obtenido se concentró usando un rotavapor. La identificación y cuantificación de los PAH se llevó a cabo usando un cromatógrafo de gases acoplado a un espectrómetro de masas (GC-MS).

El método de identificación y cuantificación fue desarrollado en nuestro grupo de investigación [4].

\section{Resultados}

En la Figura 1 se muestra el rendimiento a hollín, gases y PAH, para los cuatro isómeros analizados. El rendimiento a hollín se incrementa al aumentar la temperatura de reacción (Figura 1a), mientras que el rendimiento a gases y PAH disminuye (Figuras $1 \mathrm{~b}$ y 1c).

La tendencia general de formación de hollín es: terc-butanol $>2$-butanol $>$ 1-butanol $>$ iso-butanol, excepto a $1475 \mathrm{~K}$ donde la cantidad de hollín encontrada a partir del iso-butanol es ligeramente mayor que la del 1-butanol.

El rendimiento a PAH en función de la temperatura de pirólisis, Figura 1c, no presenta una clara tendencia para los cuatro isómeros. Para las temperaturas de 1275 y $1475 \mathrm{~K}$ es el 2-butanol el compuesto que presenta mayor rendimiento a $\mathrm{PAH}$, mientras que a la temperatura de $1375 \mathrm{~K}$ la formación de PAH a partir de 1-butanol es ligeramente superior que la correspondiente a los otros isómeros de butanol.

En cuanto a la especiación de los PAH formados, en la Figura 2 se muestra la concentración de los 16 $\mathrm{PAH}$-prioritarios para las diferentes temperaturas consideradas en este trabajo. Se puede observar como los PAH más ligeros, entre $\mathrm{C}_{10^{-}} \mathrm{C}_{16}$, presentan una mayor formación que los demás compuestos (excepto: Acenafteno, Fluoreno y Antraceno). Entre los PAH ligeros, el Naftaleno y el Acenaftileno son los PAH mayormente cuantificados en la pirólisis de todos los isómeros del butanol.

Por otro lado, aunque los PAH de alto peso molecular $\left(\mathrm{C}_{18}-\mathrm{C}_{22}\right)$ están presentes en muy baja concentración, se puede observar que son Benzo [a] pireno, Indeno $[1,2,3-\mathrm{c}, \mathrm{d}]$ pireno y Benzo [g,h,i] perileno, los formados en concentración más alta.

\section{Conclusiones}

La tendencia de formación de hollín y PAH es diferente en función del isómero de butanol considerado, siendo terc-butanol el isómero que tiene más tendencia a formar hollín, seguido por 2butanol, 1-butanol e iso-butanol.

Los PAH formados en mayor proporción, a partir de la pirólisis de los cuatro isómeros de butanol analizados, fueron los PAH entre $\mathrm{C}_{10}$ a $\mathrm{C}_{16}$, de éstos sobresalen el Naftaleno y el Acenaftileno.

Entre los PAH con $\mathrm{C}_{18}$ a $\mathrm{C}_{22}$, el Benzo [a] pireno, Indeno $[1,2,3-\mathrm{c}, \mathrm{d}]$ pireno y Benzo [g,h,i] perileno, presentan la más alta concentración.

\section{Agradecimientos}

Los autores agradecen a MINECO y FEDER (Proyecto CTQ2015-65226) y al Gobierno de Aragón y Fondo Social Europeo (Grupo GPT) la financiación recibida. Fausto Viteri agradece a la Secretaría Nacional de Educación Superior, Ciencia, Tecnología e Innovación (SENESCYT) de Ecuador, la beca predoctoral otorgada.

\section{REFERENCIAS}

[1]. MINGFA, Y., HU, W., ZUNQING, Z., and YAN, Y. Experimental study of n-butanol additive and multiinjection on $\mathrm{HD}$ diesel engine performance and emissions. Fuel. 2010, 89, 2191-2201.

[2]. LENNOX, S., LUKÁCS, K., TOROK, A., AKOS, B., MAKAME, M., ANTAL, P., and ANDREI, K. Combustion and emission characteristics of $n$ butanol/diesel fuel blend in a turbo-charged compression ignition engine. Fuel. 2013. 107, 409418.

[3]. ESARTE, C., ABIÁN, M., MILlERA, Á, BILBAO, R., and ALZUETA, M.U. Gas and soot products formed in the pyrolysis of acetylene mixed with methanol, ethanol, isopropanol or n-butanol. Energy. 2012, 43, 37-46.

[4]. SÁNCHEZ, N.E., SALAFRANCA, J., CALLEJAS, A., MILlERA, Á, BILBAO, R., and ALZUETA, M.U. Quantification of polycyclic aromatic hydrocarbons (PAHs) found in gas and particle phases from pyrolytic processes using gas chromatography-mass spectrometry (GC-MS). Fuel. 2013, 107, 246-253. 

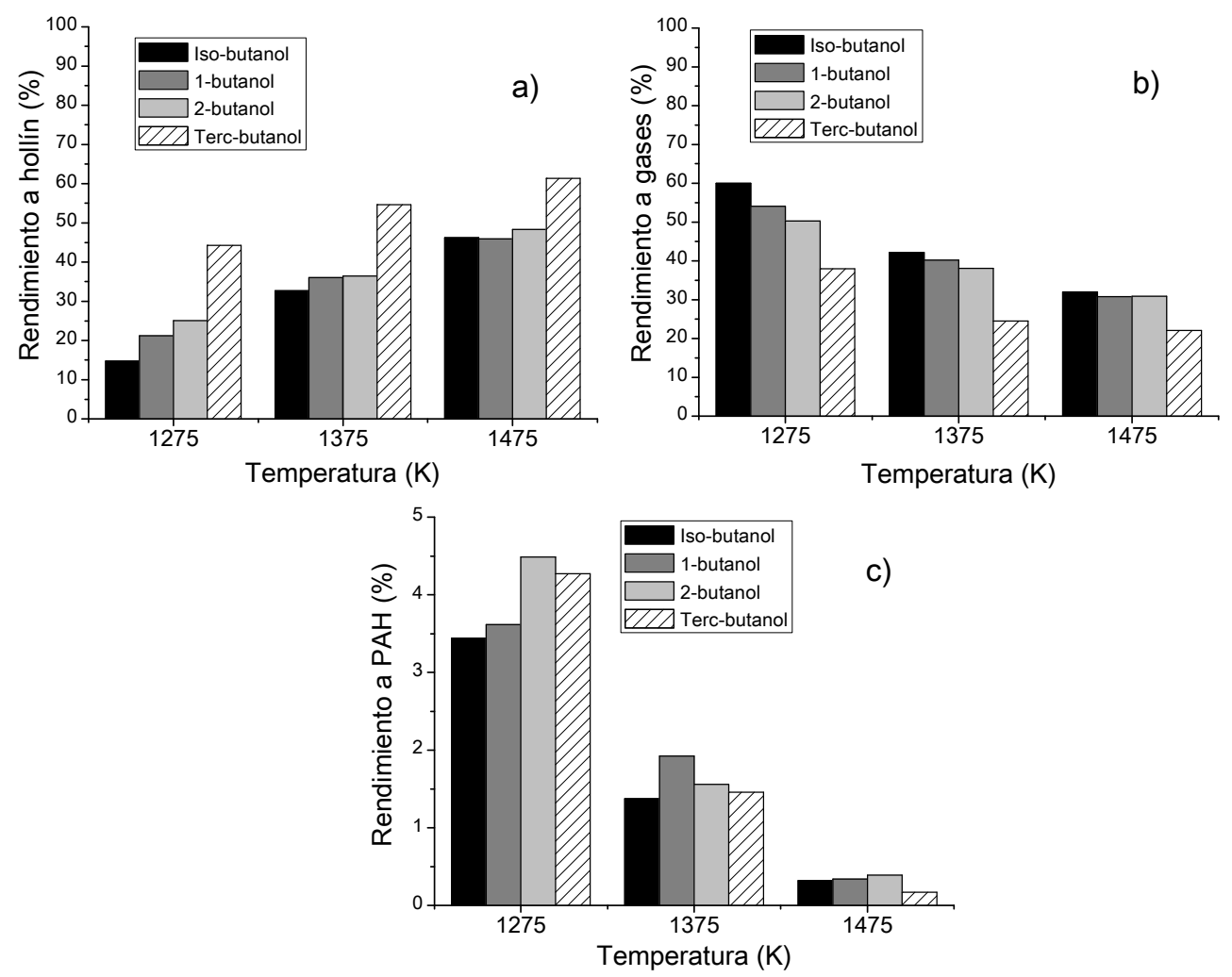

Figura 1. a) Rendimientos a hollín, b) Rendimientos a gases y c) Rendimientos a PAH, obtenidos a partir de la pirólisis de diferentes isómeros de butanol a 1275, 1375 y $1475 \mathrm{~K}$.
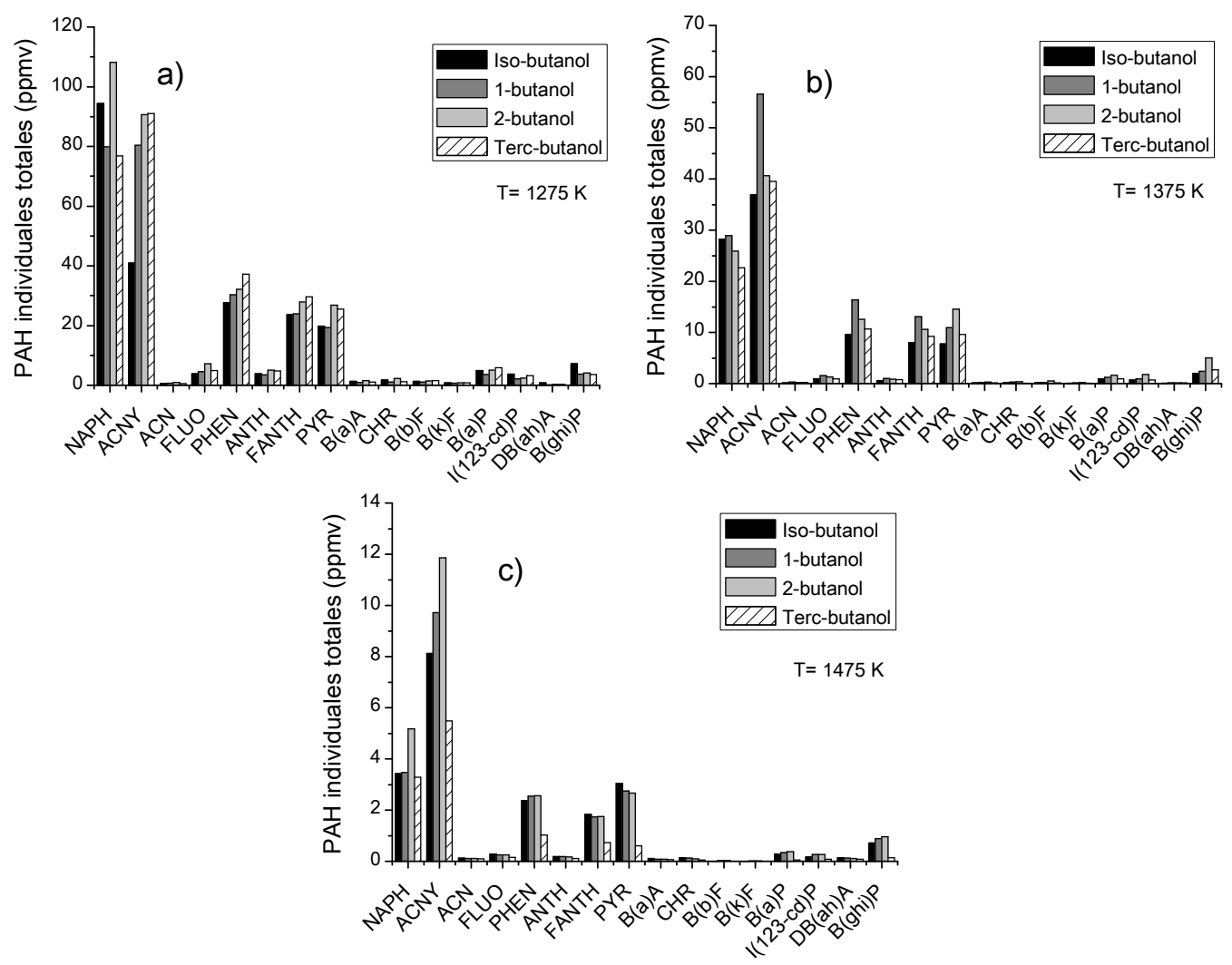

Figura 2. Especiación de los PAH cuantificados a partir de la pirólisis de los isómeros de butanol a diferentes temperaturas: a) $1275 \mathrm{~K}$, b) $1375 \mathrm{~K}$ y c) $1475 \mathrm{~K}$. 